ÁMBITOS. № 17 - Año 2008 (pp 37-57)

\title{
TELEVISIÓN DIGITAL TERRESTRE LOCAL EN GALICIA
}

\author{
Mercedes Román Portas \\ (Universidad de Vigo) \\ mroman@uvigo.es
}

\section{Resumen:}

El objetivo de este artículo es dar a conocer el panorama de la Televisión Digital Terrestre Local (TDT-L) en Galicia tras las concesiones de licencias. En concreto interesa determinar cómo afecta a Galicia el tránsito a la televisión digital. Si hay televisiones locales que llevan tiempo emitiendo pero que tienen que dejar de hacerlo por no haber conseguido licencias de televisión digital. Si hay empresas a las que se les han concedido licencias, pero no tenían hasta ahora televisión analógica. $Y$ si en el nuevo mapa de demarcaciones, hay alguna en la que hasta ahora no haya habido televisión local.

Palabras clave: Televisión digital, local, concesiones, demarcaciones.

\section{Abstract:}

The objective of this piece is to explain the outlook of the Local Digital Terrestrial Television (TDTL) in Galicia after the recent decision on government franchises. Specifically it is interesting to determine how it affects the transition from analog to digital television in local TV channels in Galicia: if some local TV stations that have been broadcasting for years have to stop their activity as a result of not getting a franchise, or some others that didn't have an analog broadcasting channel now they get a digital terrestrial one or if in the new demarcation map some areas that didn't have a local TV station have one now.

Key words: Digital television, local, franchises, demarcation.

\section{INTRODUCCIÓN}

a reciente legislación y la nueva tecnología digital obligan a cambios y conviene conocerlos. Estos cambios tienen implicaciones prácticas para las empresas propietarias de las televisiones locales (TVL), para los ayuntamientos si la televisión es municipal, para los anunciantes y para el público. El tema investigado parece relevante para el conocimiento de la historia de la comunicación de Galicia. Tiene proyección social ya que responde a las demandas de la sociedad y los resultados previsibles de esta investigación pueden ser de interés para diversos sectores. Además el conocimiento de las empresas o instituciones que van a intervenir en el nuevo panorama es fundamental para propietarios, comunicadores y público.

Una de las primeras cuestiones que hay que afrontar es la de delimitar el marco teórico (referencial o conceptual). El ámbito de este estudio se enmarca en la 
estructura de la comunicación. Es una investigación exploratoria y descriptiva. Después de varios años en que cientos de televisiones locales emitieron en la alegalidad, en 1995 se aprobó la ley de televisión local por ondas terrestres, pero esto no sirvió para ordenar el sector, pues nunca se desarrolló el plan técnico para la concesión de frecuencias previsto por la ley. El 12 de marzo de 2004, el Consejo de Ministros aprobó el Plan Técnico Nacional de Televisión Digital Local, que por diversos motivos sufrió posteriormente alguna modificación. En julio de 2006 la Xunta de Galicia otorgó las licencias de TDT-L para Galicia.

\section{NACIMIENTO DE LA TELEVISIÓN LOCAL EN ESPAÑA}

En junio de 2005 se commemoró el 25 aniversario del nacimiento de la primera televisión local (TVL) de España. Fue la de Cardedeu (Barcelona). En esta celebración participó el entonces presidente de la Generalitat, Pascual Maragall, que visitó las instalaciones de la televisión, gestionada por la Asociación de Amigos de Rádio Televisió Cardedeu. Y en el Museu Arxiu Tomás Balvey visitó una exposición conmemorativa de este 25 aniversario de la TVL, que en aquella época rompió el monopolio de TVE.

En su discurso, Maragall destacó que la TVL del municipio se había mantenido desde hacía 25 años como la mejor expresión de la que ha denominado televisión comunitaria y la ha definido como prototipo de la televisión local al servicio de una comunidad en un ejercicio de proximidad. A las puertas de la nueva televisión digital, Maragall destacó que televisiones que han sobrevivido, como la de Cardedeu, deben tener un lugar en el nuevo mapa digital apostando por buscar y encontrar fórmulas que garanticen expectativas de futuro a la TVL.

La primera emisión de la televisión de Cardedeu fue el sábado 7 de junio de 1980 y un año después fueron muchas las poblaciones que se interesaron por crear su televisión local. Aquel día, el teatro parroquial Esbarjo de Cardedeu se convirtió en el primer plató de televisión no gubernamental de España y más de un centenar de personas se reunieron para debatir el proyecto de RTV Cardedeu. El acto se vio por el canal 51, en directo y en diferido, con dos horas de emisión que incluyeron la representación de un fragmento del Tartufo de Moliére.

Un año después de aquel acto, en 1981, y tras diversas pruebas de emisiones esporádicas, se preparaba la inauguración oficial de la televisión de Cardedeu, pero una treintena de guardias civiles se presentaron en los locales de la emisora para clausurarla. A pesar de ello, se inauguró de forma simbólica RTV Cardedeu con la presencia del presidente del parlamento catalán. Durante los meses posteriores, se recibieron centenares de adhesiones espontáneas al proyecto y RTV Cardedeu no dejó de emitir, a pesar de prohibiciones y cierres, y en la actualidad emite 25 horas de programación semanal ${ }^{1}$.

Sobre la evolución histórica de las televisiones locales se pueden ver tres artículos de la autora de este trabajo. "Televisiones locales de Galicia” (1997); "La televisión local en el Estado Español” (2003) y "La televisión local en España” (2005). 


\section{NATURALEZA DE LA TELEVISIÓN LOCAL DESDE EL PUNTO DE VISTA LEGISLATIVO}

Para determinar qué se entiende por TVL hemos de fijarnos en el ámbito de cobertura y en los contenidos. La legislación debe establecer nítidamente qué se entiende por TVL, cuál es su naturaleza en cuanto a ámbito de cobertura y en cuanto a los contenidos mínimos de producción propia para que se pueda considerar emisora local, ya que el carácter local de una televisión debe venir definido por los temas de los que se ocupa en su programación.

Hay que señalar que la ley 41/1995 entiende por tal aquella modalidad de televisión consistente en la emisión o transmisión de imágenes no permanentes dirigidas al público sin contraprestación económica directa por medio de ondas electromagnéticas propagadas por una estación transmisora terrenal en el ámbito territorial señalado en el art. 3 de esta ley. También dice que Como medio audiovisual de comunicación social tiene la naturaleza de servicio público.

Vamos a detenernos en primer lugar en el aspecto de la cobertura. En la ley de 1995 se hacía referencia expresa al ámbito de cobertura de TVL. El art. 3.1. señalaba que El ámbito territorial cubierto por cada una de las TVL por ondas terrestres vendrá delimitado por el núcleo urbano principal de población del municipio correspondiente. Los municipios españoles tenían derecho a instalar una TVL, independientemente del número de habitantes y de la extensión territorial del municipio. El límite impuesto de núcleo urbano quedaba abierto a otros núcleos de población pero sin superar el municipio y cuando lo aconsejase el número de habitantes. Es decir el número de habitantes sería el criterio fundamental para ampliar cobertura.

Excepcionalmente, las Comunidades Autónomas podían autorizar coberturas que superasen el estricto ámbito territorial de una TVL por ondas terrestres. Tenían que reunir las siguientes condiciones: proximidad territorial, identidad social y cultural, y previa conformidad de los municipios afectados. En esta ley se prohibía la emisión en cadena, pero se contemplaban circunstancias en las que las TVL podían llegar a acuerdos para emitir en cadena algunas horas al día. Se entenderá que emiten en cadena aquellas televisiones locales que emitan la misma programación durante más del $25 \%$ del tiempo total de emisión semanal, aunque sea en horario diferente. También se abría otra posibilidad de emisión en cadena, sin restricciones territoriales, ni de número de emisoras con la condición de que no excediese el $25 \%$ de horas semanales de emisión de cada una de las TVL.

En cuanto a los contenidos y horarios en la ley de 1995 se señalaba que el tiempo de emisión, el contenido de la programación de este servicio de televisión local por ondas terrestres y otras cuestiones de la competencia de las Comunidades Autónomas podrá ser fijado por éstas, dictando al efecto las oportunas normas reguladoras.

Pasaron 7 años, hasta el 2002, para que se hiciese la primera reforma, pero ya dentro de la tecnología digital. Mientras tanto, no se regularizó el sector, no hubo

\footnotetext{
${ }^{1}$ Cfr.http://actualidad.terra.es/sociedad/articulo/conmemoran_aniversario_nacimiento_television_local_3 40415.htm [Consulta: 26 de marzo de 2007].
} 
concesiones, se crearon emisoras, otras se traspasaron o se vendieron, se establecieron cadenas y se emitió en cadena. Algunas Comunidades Autónomas hicieron sus correspondientes decretos.

Cuadro 1. Modelo de TVL según criterios de horarios de emisión, porcentaje de producción propia y cobertura.

\begin{tabular}{|c|c|c|c|c|c|c|}
\hline $\begin{array}{c}\text { COMUNIDADES } \\
\text { AUTÓNOMAS }\end{array}$ & $\begin{array}{c}\text { HORAS } \\
\text { DIARIAS }\end{array}$ & $\begin{array}{c}\text { HORAS/ } \\
\text { SEMANA }\end{array}$ & $\begin{array}{c}\text { PRODUCCION } \\
\text { PROPIA }\end{array}$ & $\begin{array}{c}\text { COPRODUCCIÓN } \\
\text { TERCEROS }\end{array}$ & $\begin{array}{c}\text { ÁMBITO DE } \\
\text { COBERTURA }\end{array}$ & $\begin{array}{c}\text { EMISIÓN } \\
\text { EN CA- } \\
\text { DENA }\end{array}$ \\
\hline NAVARRA & NO & NO & NO & MUNICIPAL & NO \\
\hline CATALUÑA & 1 & 7 & $60 \%$ & $40 \%$ & MUNICIPAL & NO \\
\hline $\begin{array}{c}\text { CASTILLA } \\
\text { LA MANCHA }\end{array}$ & 2 & 14 & $40 \%$ & $25 \%$ & MUNICIPAL & NO \\
\hline $\begin{array}{c}\text { ANDALUCIA } \\
\text { EXTREMADURA } \\
\text {-5.000 HAB. }\end{array}$ & 4 & NO & 42 & $50 \%$ & $50 \%$ & MUNICIPAL \\
\hline
\end{tabular}

Fuente. Maneiro, 2001: 37.

Como señalaré después, la ley de 30 de diciembre de 2002 de "Medidas fiscales, administrativas y del orden social", modificó la de 1995. Esta ley justifica la reforma por la necesidad de dar un paso más en la implantación de la TDT. De hecho la TVL aparece ahora como el primer sector que debe hacer la transición a tecnología digital, como condición imprescindible para su legalización o regularización. Se entiende por tal (TVL) exclusivamente a los efectos de Ley aquella modalidad de televisión consistente en la emisión o transmisión, con tecnología digital, de imágenes. No se preestablece un ámbito de cobertura, ya que el el ámbito de cobertura de cada canal múltiple reservado para la cobertura local será el establecido en cada caso en el Plan Técnico Nacional de la Televisión digital local.

Las comunidades autónomas debían ser las que solicitasen cobertura para unos ámbitos territoriales determinados o demarcaciones. Pero sería la Administración Central quien aceptase las peticiones y quien estableciese las demarcaciones definitivas para las TVL. Los límites ya no eran municipales, sino que dependería del número de habitantes, de las dimensiones del territorio que se quería cubrir y de las disponibilidades técnicas. En un primer nivel aparecían con derecho a tener canales de TDT-L las capitales de provincia y los municipios con más de 100.000 habitantes. En Galicia cumplen estas condiciones A Coruña, Lugo, Ourense, Pontevedra, Vigo, Santiago y Ferrol. Para ver cuántas más podrían emitir, había que esperar a la aprobación del Plan Técnico Nacional de TDT-L. La Xunta de Galicia podía pedir licencias para demarcaciones formadas por municipios colindantes cuya población fuese superior a 25.000 habitantes o cuya cobertura incluyese a todos los municipios de un radio de al menos 25 kilómetros cuadrados. Por tanto la TDT-L pasa de tener una cobertura municipal a comarcal. 
En la ley de 30 de diciembre de 2003 de acompañamiento de presupuestos generales del Estado para 2004, se autorizó la emisión en cadena. Esta ley concreta que los adjudicatarios de licencia de TVL podían utilizar tecnología analógica para la difusión de sus emisiones durante dos años a contar desde el 1 de enero de 2004, aunque se habilita al Gobierno para cambiar el plazo a la vista del desarrollo y penetración de la tecnología digital de difusión de televisión por ondas terrestres. También se modifican las disposiciones relativas al ámbito territorial, correspondiendo al Gobierno la aprobación del Plan Técnico Nacional de la TDT-L, a la vista de las solicitudes presentadas por las comunidades autónomas y teniendo en cuenta las frecuencias disponibles. Además, el Plan Técnico determinaría los canales múltiples necesarios y los ámbitos de cobertura de dichos canales múltiples destinados a la difusión de los servicios de televisión local.

Esta ley concreta que los titulares de concesiones estarán obligados a emitir programas televisivos originales durante un mínimo de cuatro horas diarias y treinta y dos semanales, no considerándose programas televisivos las emisiones consistentes en imágenes fijas ni los tiempos destinados a la publicidad, televenta y juegos, y concursos promocionales, ni programas originales aquellos que consistan en la mera reemisión de programas televisivos cuya difusión se haya realizado por otro medio.

En España, la información es la base de los contenidos de las televisiones locales. Además, como se ha constatado a partir de investigaciones sobre distintas comunidades autónomas, la demanda informativa de los ciudadanos es uno de los motivos principales que ha impulsado el nacimiento de estos medios.

Según Iglesias, en relación con la comunidad en la que se asienta, la información de proximidad debe cumplir importantes funciones:

1. Facilitar la participación y el debate social.

2. Representar la realidad local y regional como distintas y relacionadas con la realidad nacional y transnacional.

3. Presentar e interpretar las noticias y las crónicas sobre política, cultura y economía nacional e internacional a partir de las claves de selección y de referencias basadas en las especificidades y en los intereses locales y regionales.

4. Realzar y dar visibilidad a las relaciones que la localidad (o región) mantiene con otra realidades locales (o regionales) del mismo estado e internacionales, y a los proyectos que se derivan de estas relaciones.

5. El mantenimiento de las identidades culturales.

6. La contribución a la difusión y a la consolidación de una política cultural moderna, estableciendo múltiples sinergias entre el sector audiovisual y el teatro, la música, las fiestas o el patrimonio artístico.

7. El desarrollo de una política educativa, tanto a nivel escolar y universitario como a nivel de educación permanente. 
8. Contribuir a la política de bienestar social, que implica múltiples retos en sectores como los de la tercera edad, el desarrollo rural, ámbitos tradicionalmente marginados u olvidados en las políticas de comunicación convencionales.

El mercado local de televisión tendrá una importancia relevante como nuevo espacio mediático, con lo que ello implica de atractivo para empresarios privados e instituciones públicas.

De todas las argumentaciones que se le demandan a una TVL, históricamente la que mejor responde a su filosofía es la que la asocia con unos contenidos propios; es decir, situados dentro de la realidad social de la comunidad en la que está ubicada la emisora. Éste es el verdadero sentido y la verdadera obligación, al menos en el caso de los proyectos de titularidad pública. Las televisiones de proximidad tienen una clara identificación y, por tanto, una fácil rentabilidad social y económica. Hay que reivindicar el conocimiento público de los contenidos más próximos, aquéllos que se refieren a los asuntos que más directamente nos afectan como ciudadanos de un entorno determinado. Las TVL pueden promover, utilizando este medio como principal referencia, proyectos multimedia de servicio a los ciudadanos. La integración de la televisión con la radio y con Internet puede facilitar un espacio audiovisual propio, a partir del cual se pueden desarrollar numerosas actividades de apoyo, información y entretenimiento en todos los sectores de la población.

\section{LEGISLACIÓN SOBRE TELEVISIÓN LOCAL EN ESPAÑA}

A continuación se señalan las leyes que hacen referencia a la TVL desde 1995, año en que se aprobó la primera ley referida a este medio hasta que se aprobó el Plan Técnico de Televisión Digital Local en el 2004, y sus modificaciones posteriores:

\section{Ley 41/1995 (22 de diciembre): "Televisión local por ondas terrestres".}

2. Ley 53/2002 (30 de diciembre): "Medidas fiscales, administrativas y del orden social". Es la ley de acompañamiento de los Presupuestos Generales del Estado. Es la primera modificación de la ley de 1995. Se establecieron plazos definidos y cortos para la legalización definitiva de TVL, pero siempre condicionada a la transición a tecnología digital. Esta norma sólo considera TVL legalizable a las emisoras de tecnología digital. Las comunidades autónomas cumplieron los plazos previstos hasta octubre de 2003, definieron las necesidades de espectro radioeléctrico reservado y la definición de las demarcaciones en las que podrían concederse estas televisiones como paso previo para la elaboración de un plan técnico por parte del Ministerio de Ciencia y Tecnología (plan que se aprobaría en abril de 2004).

3. Ley 62/2003 (30 de diciembre): "Medidas fiscales, administrativas y del orden social". Se concretaron tiempos (obligados a emitir programas televisivos originales durante un mínimo de cuatro horas diarias y 32 semanales) y contenidos, posibilidades de formación de cadenas y de emisión conjunta, determinación de porcentajes permitidos para emisión en cadena. Teniendo en cuenta que pasar a tecnología digital supone problemas, en la modificación de ese año se estableció una ampliación de plazos, los concesionarios de TVL podrían seguir emitiendo en analógico 
hasta que hubiese posibilidad de contar con un parque de receptores digitales en los hogares suficiente para que la TVL digital fuese rentable.

4. Real Decreto 439/2004 (12 de marzo): Aprueba el Plan Técnico Nacional de Televisión Digital Local. El Consejo de Ministros celebrado el 14 de marzo de 2004 aprobó el Plan Nacional de Televisión Digital Local que establecía 266 demarcaciones, que se decidieron de acuerdo con las frecuencias disponibles y las peticiones de las comunidades autónomas, que serían las responsables de realizar los pertinentes concursos públicos para otorgar las concesiones. En este plan se otorgaron a Galicia un total de 20 concesiones para televisión digital local. La comunidad que más concesiones recibió fue Andalucía con 58 demarcaciones, seguida de CastillaLa Mancha con 25 y Castilla y León con 21, según informa el Ministerio de Ciencia y Tecnología. Cada una de las emisoras tendría un canal múltiple con capacidad para cuatro programas. Serán más de mil las cadenas de TDT-L que podrán operar legalmente en España, hasta llegar al $87 \%$ de la población. El plan establecía canales múltiples para obtener la cobertura de las capitales de provincia y autonómicas y de los municipios con una población superior a 100.000 habitantes. Adicionalmente, se contempla también la cobertura de municipios con una población inferior a esa cifra cuando haya frecuencias disponibles. Los concursos para la asignación de las concesiones correspondientes a las demarcaciones que contempla este plan serían convocados y resueltos por las comunidades autónomas. Correspondía a la Agencia Estatal de Radiocomunicaciones establecer las características técnicas de las estaciones, así como aprobar los proyectos técnicos de las instalaciones. Los ayuntamientos podrán ser titulares de uno de los programas (de los cuatro que componen cada canal múltiple) o ceder todos a titularidad privada. La decisión sobre el modo de gestión corresponderá a los municipios incluidos dentro de la demarcación, atendiendo a criterios de población. En el mes de julio de 2004 nueve organizaciones de televisiones locales pidieron la paralización del Plan Nacional de la TDT-L. Fue en el marco del V Mercado Audiovisual de Catalunya y a raíz del encuentro de Televisiones Locales españolas que se había celebrado en mayo. Las organizaciones de TVL tanto públicas como privadas que asistieron al acto firmaron un manifiesto ${ }^{2}$ en defensa de la televisión de proximidad. En este texto se solicitaba al Gobierno central la creación urgente de una Mesa del Sector de la TVL para que, entre otras cosas, se paralizase transitoriamente el Plan Técnico Nacional de la TDT-L y se revisasen tanto sus contenidos como los de la Ley. También se solicitaba que se garantizase la continuidad de las televisiones locales.

5. El Consejo de Ministros aprobó el 3 de diciembre de 2004 un decreto que modificó el Plan Técnico Nacional de la Televisión Digital Local, y que situaba en el 1 de enero de 2008 la nueva fecha límite para el apagón analógico, momento en el que sólo se podrá emitir en digital. El decreto establecía una nueva fecha límite para completar todo el proceso de adjudicación de las concesiones de televisión digital local, que debería finalizar el 4 de agosto de 2005. Las modificaciones se justificaban como consecuencia de las necesidades y peticiones realizadas por las Comunidades Autónomas. De este modo, el Real Decreto introdujo modificaciones en lo relativo al ámbito de coberturas, a las demarcaciones, a los plazos para convocar y adjudicar las concesiones y a la fecha límite del así llamado apagón analógico.

\footnotetext{
2 http://www.g9tvlocal.com/base.swf [Consulta: 27 de marzo de 2007].
} 
Cuando se aprobó el Plan Técnico en marzo de 2004 varias comunidades autónomas pusieron de manifiesto, por una parte, la necesidad de realizar ciertos ajustes en algunas de las demarcaciones, y, por otra, la de disponer de canales múltiples adicionales en algunas demarcaciones. Casi todas las comunidades autónomas habían manifestado dificultades con los plazos de los cuales disponían para convocar los concursos y para adjudicar las concesiones de TDT-L, ya que se debían adoptar decisiones y llevar a cabo procesos de adjudicación complejos que, en la mayoría de los casos, afectan a más de un municipio. Con el fin de fijar fechas más realistas para realizar el tránsito de la tecnología analógica a la digital, se incluyó una disposición transitoria para ampliar el plazo en dos años, contados desde el 1 de enero de 2006, durante el cual los concesionarios de licencias de TDT-L, otorgadas en los concursos convocados por las comunidades autónomas, podrían realizar emisiones con tecnología analógica, siempre que así lo permitieran las disponibilidades del espectro radioeléctrico. Con ello, la nueva fecha límite para el apagón analógico será el día 1 de enero de 2008. Hasta octubre de 2005 únicamente las comunidades autónomas de Baleares y de Madrid habían convocado los concursos para la adjudicación de las concesiones de TDT-L. Respondiendo a las solicitudes de las comunidades autónomas, el Real Decreto que modifica el Plan Técnico Nacional de Televisión Local amplia los ámbitos de cobertura de 45 demarcaciones y añade 15 nuevas, con lo que el total de demarcaciones del Plan pasa de 266 a 281. Y en Galicia de 20 a 21 al añadirse la demarcación de As Pontes.

6. Ley 10/2005 (14 de junio): "Medidas Urgentes para el Impulso de la Televisión Digital Terrestre, de Liberalización de la Televisión por Cable y de Fomento del Pluralismo". Confirma y amplía el derecho preferente de los ayuntamientos para gestionar de forma directa sus televisiones.

\section{PRINCIPALES MAGNITUDES DE LA TELEVISIÓN LOCAL EN GALICIA. LEGISLACIÓN SOBRE TELEVISIÓN DIGITAL LOCAL EN GALICIA}

Resulta interesante comparar la evolución mensual del consumo diario medio de televisión en Galicia y en el resto de España. Como se observa en el gráfico 1, la evolución desde agosto del 2002 a noviembre del 2006 es bastante parecida cada año, atendiendo a los meses. La evolución en España y en Galicia es casi paralela, teniendo en cuenta que los datos de Galicia son algo inferiores. 
Gráfico 1. Evolución mensual del consumo diario medio de televisión en Galicia y España.
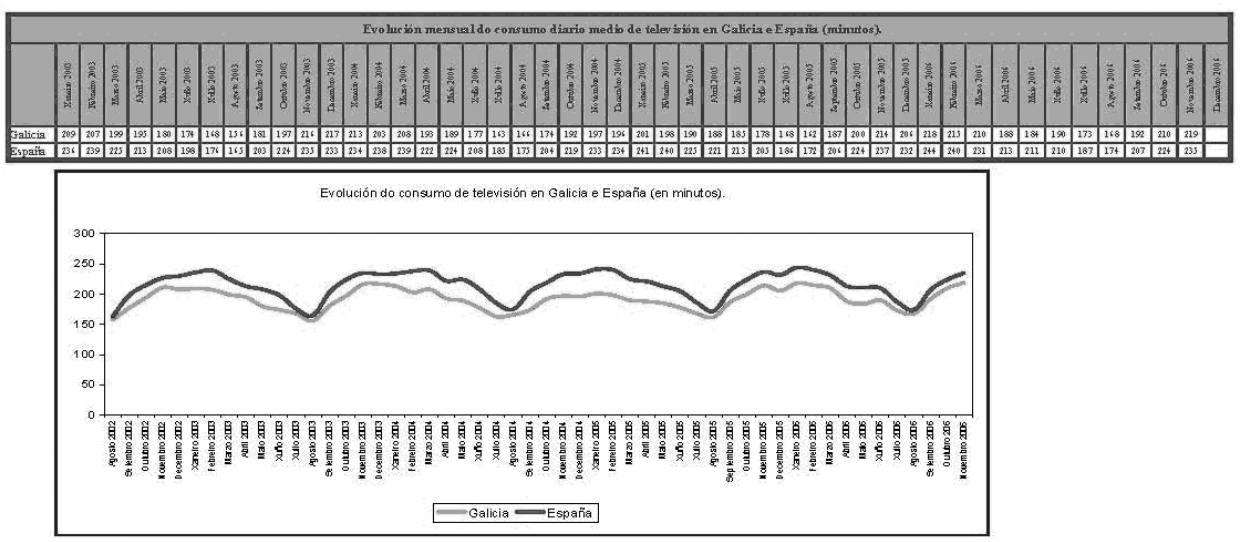

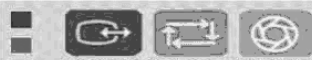

- obSERVATORIO audiuVisual galtgu

\section{XUNTA DE GALICIF}

PRESIDENCIA

Secretaria Xeral de Comunicación

Dirección Xeral de Comunicación Audiovisual

También disponemos de datos sobre las principales magnitudes de la televisión local en Galicia en los años 1997 y 2003. En concreto, la facturación de esas televisiones, el número de empleados, el número de empresas, la distribución por provincias de las televisiones locales gallegas en el 2003. Como muestra el gráfico 2, la facturación entre esos dos años aumentó un 105\% en las TVL. El número de empleados aumentó un $94 \%$ y el número de empresas un $50 \%$.

Gráfico 2. Principales magnitudes de televisión local en Galicia.

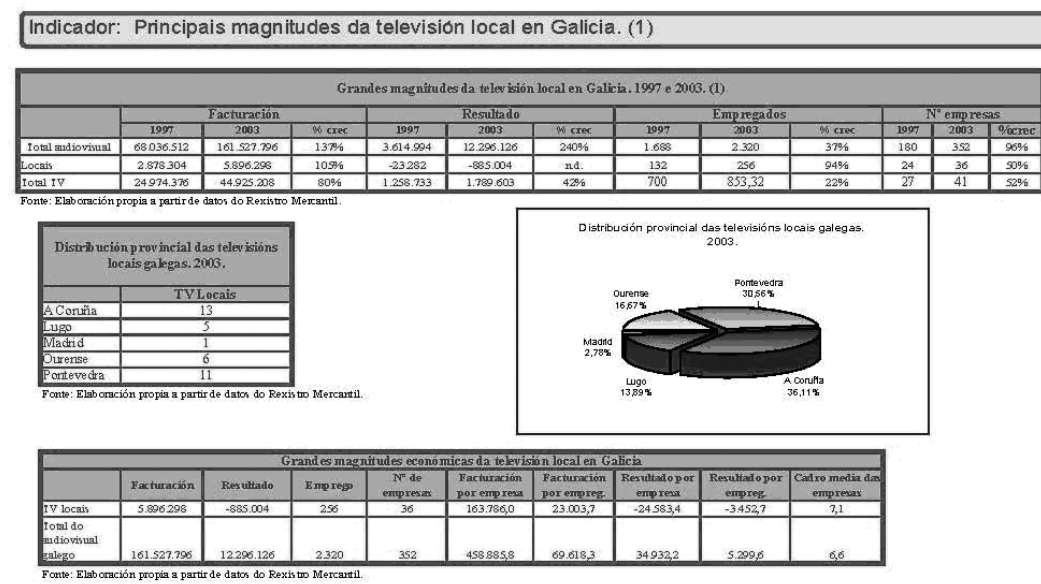


En cuanto a la facturación de las TVL gallegas disponemos de datos desde el año 1995 hasta el 2003 y podemos compararlos con la facturación total de la televisión en esa comunidades autónomas en esos mismos años. Observamos que la facturación siempre fue en aumento. En cuanto al número de empleados, siempre fue en aumento a excepción del 2000 y 2001 en el que esta cifra descendió.

Gráfico 3. Principales magnitudes de televisión local en Galicia.
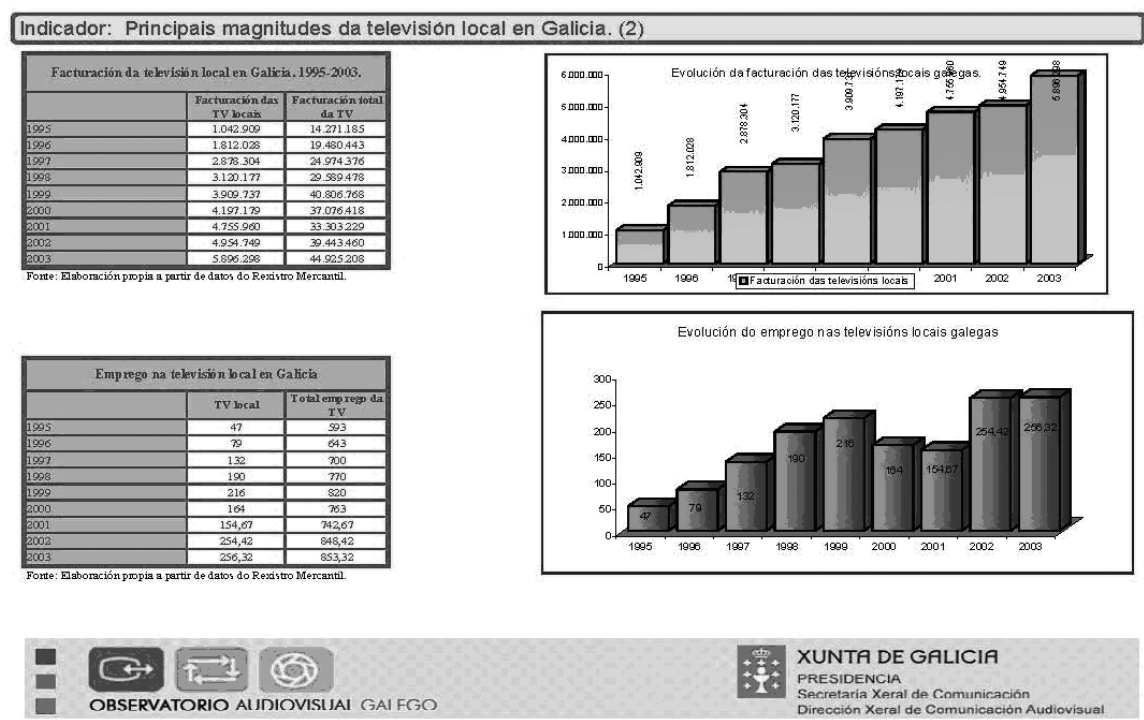

XUNTA DE GALICIA

PRESIDENCIA

Secretaria Xeral de Comunicación

Dirección Xeral de Comunicación Audiovisual

En cuanto a la audiencia, disponemos de los datos de audiencia de las distintas cadenas de televisión españolas desde 1998 a 2005 y de las televisiones locales del 2004 y 2005 . En el año 2004 las locales tuvieron una cota de audiencia del 2,20 $\%$, mientras que Telecinco fue la cadena con la cota más alta en Galicia con un 23,90\%. En el año 2005 la cota de las locales subió a un 2,70\% y Telecinco continuó siendo la primera con un $23,90 \%$. 
http://dx.doi.org/10.12795/Ambitos.2008.i17.03

Mercedes Román Portas

Gráfico 4. Datos de audiencia de televisión en Galicia por cadena (share) 1995-2005.

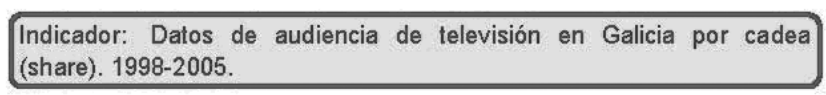

\begin{tabular}{|c|c|c|c|c|c|c|c|c|}
\hline \multicolumn{9}{|c|}{ Co ta de audiencia de televisión en Galicia. 1998-2005. } \\
\hline & 1998 & 1999 & 2000 & 2001 & 2002 & 2003 & 2004 & 2005 \\
\hline TV 1 & 27,90 & 27,20 & 27,30 & 28,20 & 28,50 & 25,70 & 21,90 & 20,00 \\
\hline La 2 & 8,20 & 7,70 & 7,0 & 7,90 & 8,10 & 7,80 & 7,50 & 6,10 \\
\hline Tele 5 & 22,20 & 21,90 & 21,20 & 20,50 & 20,50 & 22,70 & 23,90 & 23,90 \\
\hline Antena 3 TV & 19,80 & 19,90 & 20,00 & 19,30 & 19,70 & 19,50 & 20,00 & 21,20 \\
\hline Cuatro & - & - & - & - & - & - & - & 0,90 \\
\hline TVG & 18,10 & 18,60 & 19,00 & 18,30 & 16,70 & 18,00 & 17,40 & 17,30 \\
\hline Canal + & - & - & - & - & - & 2,60 & 2,20 & 1,80 \\
\hline Temáticas & - & - & - & - & - & 360 & 4,80 & 6,10 \\
\hline Locales & $=$ & $=$ & - & $=$ & - & 3,00 & 2,20 & 2,70 \\
\hline
\end{tabular}

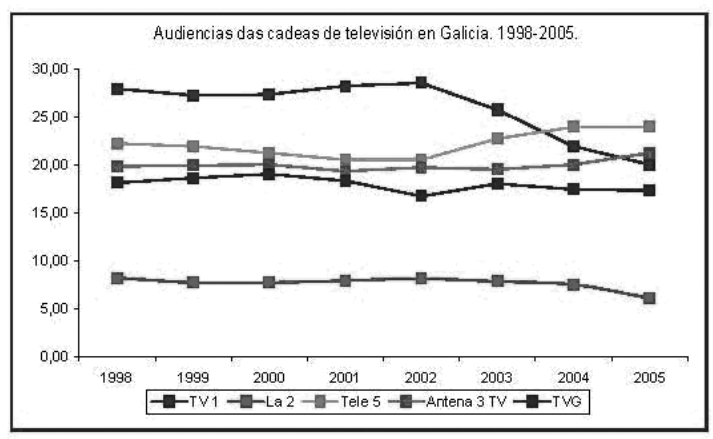

Fuente: Observatorio Audiovisual Galego.

Y, por último, disponemos de los datos de perfiles de audiencia de la televisión en Galicia, como muestra el gráfico 5. 
Gráfico 5. Perfil de audiencia de televisión en Galicia en 2005.

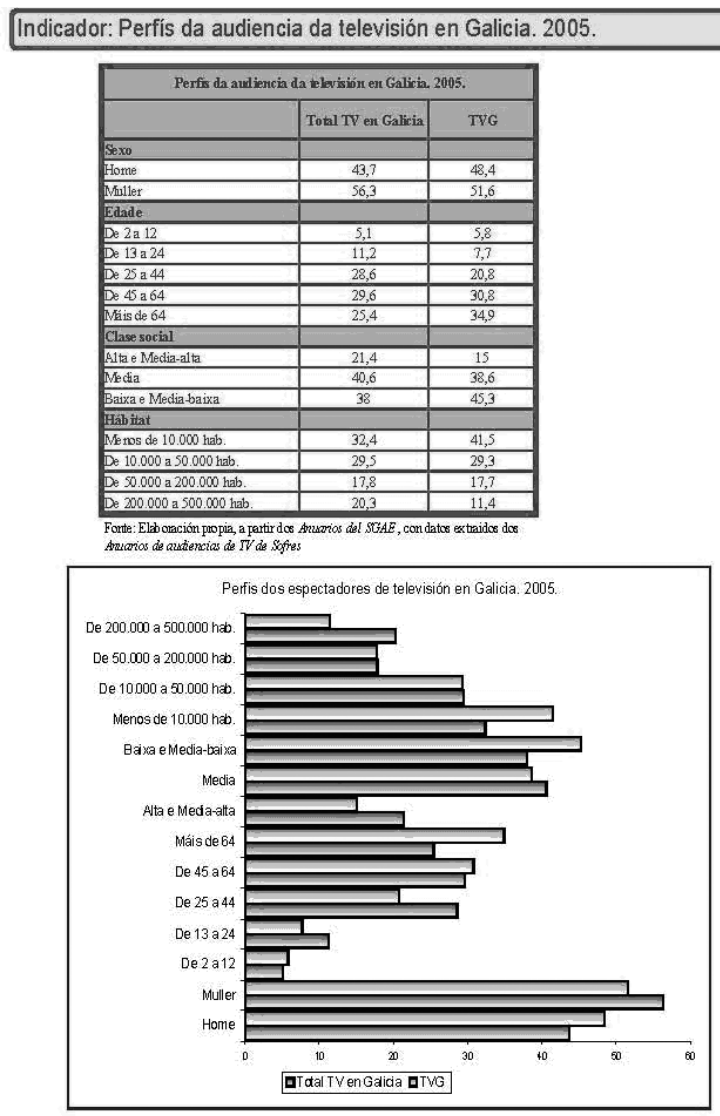

Fuente: Observatorio Audiovisual Galego.

En cuanto a la legislación, en abril de 2005 se aprobó el Decreto 81/2005 (14 de abril) por el que se regula el régimen jurídico de gestión del servicio público de televisión digital en la Comunidad Autónoma de Galicia en el que se incluye lo referente a la televisión digital local.

En julio de 2006, y con un año de demora, el gobierno gallego llevó a cabo la concesión de 46 licencias de TDL, 6 emisoras autonómicas de radio y 66 emisoras de radio de carácter municipal.

\section{CONCESIONES EN GALICIA}

La decisión estaba pendiente desde hacía un año. Esto se debió al cambio de Gobierno en las elecciones autonómicas del año 2005. Quedaron pendientes las concesiones de TDT-L y las radios digitales autonómicas y locales. El gobierno bipartito demoró un año la decisión. En julio de 2006 la Xunta de Galicia adjudicó las emisoras digitales de cobertura local. Se presentaron 87 ofertas para 21 demarca- 
ciones territoriales (véase gráfico 6), desde un máximo de once propuestas para Santiago hasta el otro extremo en el caso de As Pontes, donde el concurso quedó desierto. La Xunta aprobó un total de 46 licencias. En este reparto, como vamos a ver, Localia y Prensa Ibérica fueron los principales beneficiarios en el mapa de la TDT-L.

Localia, perteneciente al grupo Prisa, ya venía emitiendo en analógico. Recibió concensión digital en A Coruña, Lugo, Ourense, y Vigo a través de la empresa Unión Temporal de la Televisiones Gallegas (Utega), mientras que en Ferrol tendrá presencia a través de Radio Coruña S.L. y en Santiago con Compostelavisión S.L. Destaca también el acceso en las ciudades del grupo del Faro de Vigo (Prensa Ibérica). Asimismo, varias emisoras locales que funcionaban de forma estable en analógico deberían cerrar la emisión al no recibir licencia.

Gráfico 6. Demarcaciones de televisión digital terrestre de ámbito local.

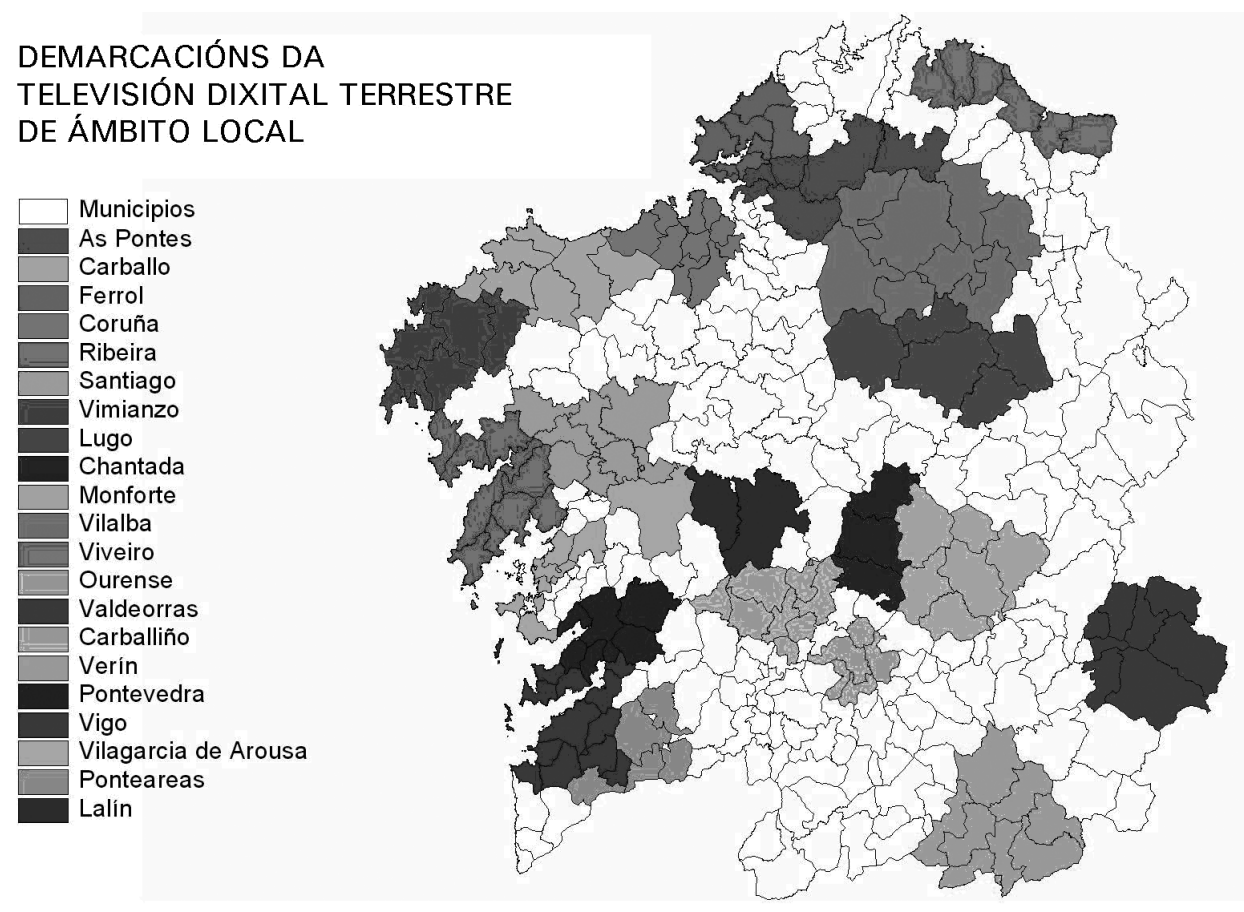

Fuente: http://www.xunta.es.

Del accionariado de Utega, con mayoría de la Cadena Ser y el grupo Prisa, venía formando parte también la editorial Prensa Ibérica, con la tercera parte de las acciones. Por otra parte, Prensa Ibérica, editor de los periódicos Faro de Vigo y La Opinión, recibió concesión para TDT-L a través de Faro de Vigo S.A.U. y de La Opinión S.L. en A Coruña, Ferrol, Santiago, Ourense, Pontevedra, Vigo y Carballo. En esta misma comarca podrá emitir el proyecto de Editorial La Capital S.L. editora de los periódicos El Ideal Gallego, Diario de Bergantiños, Diario de Arousa y Diaro de Ferrol y que recibió licencia de TDT-L en cada una de esas áreas de actuación. Otro grupo 
de comunicación relevante, el Grupo Correo, accedió a través de Editorial Compostela a las licencias de Santiago, Vimianzo, Ribeira y Lalín.

Entre las situaciones paradójicas creadas por esta concesión de TDT-L está la situación de algunos canales que ya emitían en analógico y más o menos estaban estabilizadas en sus contornos locales, como es el caso de la televisión de Ferrol Canal 31 en la comarca de Ferrol, o de Código TV en el área compostelana.

La lista completa de licencias de TDT-L concedidas es la siguiente:

\section{A Coruña}

- Carballo: La Opinión de La Coruña, S.L., Editorial La Capital, S.L. e Salitre Multimedia.

- Coruña: La Opinión de La Coruña S.L., Editorial La Capital S.L. e Utega S.A.

- Ferrol: La Opinión de La Coruña S.L., Editorial La Capital S.L. e Radio Coruña S.L.

- Ribeira: Editorial Compostela S.A., Multimedia Comunicaciones e TV Mancomunidade do Salnés.

- Santiago: Faro de Vigo, S.A.U., Compostelavisión S.L. e Editorial Compostela S.A.

- Vimianzo: Editorial Compostela S.A.

- As Pontes: declarada deserta.

\section{Lugo}

- Chantada: Chantada Comunicación S.L.

- Lugo: Telelugo El Progreso de Lugo S.L., Utega S.A. y Alternativas de Medios Audiovisuales.

- Monforte: Telelugo El Progreso de Lugo S.L., Telemiño S.A. y TV7 Monforte S.A.

- Vilalba: Telelugo El Progreso de Lugo S.L. y TV7 Monforte S.A.

- Viveiro: Telelugo El Progreso de Lugo S.L.

\section{Ourense}

- Barco de Valdeorras: Telemiño S.A.

- Carballiño: Telemiño S.A.

- Ourense: Telemiño S.A., Faro de Vigo S.A. y Utega S.A.

- Verín: Telemiño S.A.

\section{Pontevedra}

- Lalín: Editorial Compostela S.A., Multimedia Comunicaciones e Deza Visión S.A. ${ }^{3}$.

- Ponteareas: Rías Baixas de Produción e Josefa López Pousa.

- Pontevedra: Faro de Vigo S.A.U., Lérez Canal 29, S.L. e Televisión Pontevedra.

- Vigo: Faro de Vigo S.A.U., Utega S.A. e Rías Baixas de Produción.

- Vilagarcía de Arousa: Lérez Canal 29 S.L., TV Salnés e Editorial La Capital S.L.

\footnotetext{
3 Pertenece a UNE, red de televisiones locales, el grupo Atlas y Telecinco.
} 
En color se muestra cada una de las demarcaciones y la frecuencia en la que emitirán los concesionarios privados más un canal público en cada demarcación.

Gráfico 7. Demarcaciones de Galicia.

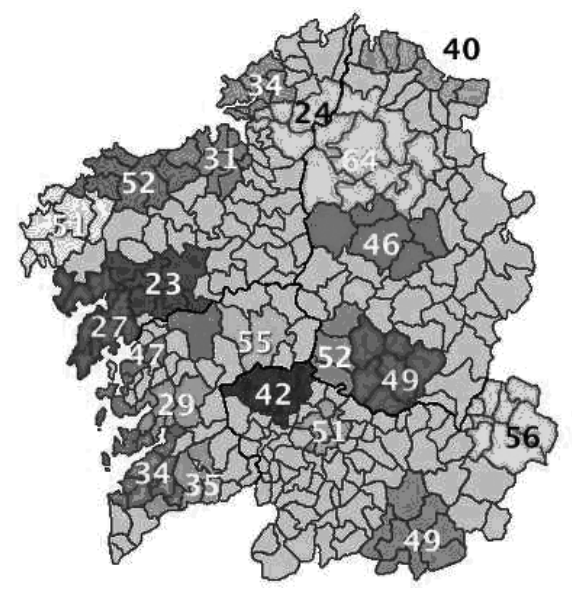

Fuente: http://www.xunta.es

En la tabla 1 se muestra la distribución de TDT-L por demarcaciones y empresa:

\begin{tabular}{|c|c|c|c|c|c|c|c|c|c|c|c|c|c|c|c|c|c|c|c|c|}
\hline & 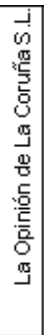 & 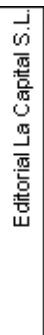 & 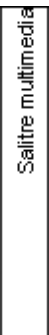 & 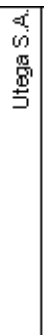 & 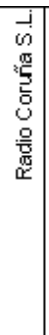 & 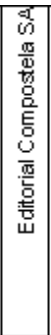 & 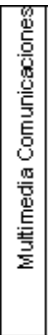 & 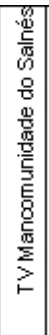 & 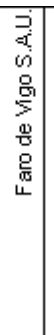 & 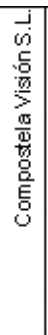 & 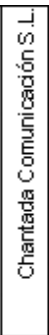 & 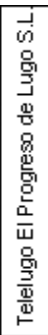 & 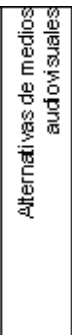 & 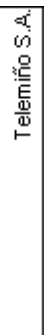 & 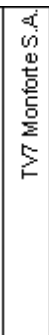 & 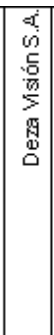 & 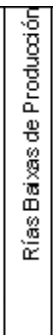 & 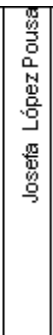 & 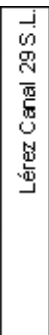 & 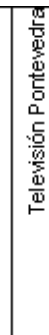 \\
\hline Carballo & $x$ & $x$ & $x$ & & & & & & & & & & & & & & & & & \\
\hline AConuña & $x$ & $x$ & & $x$ & & & & & & & & & & & & & & & & \\
\hline Ferrol & $x$ & $x$ & & & $x$ & & & & & & & & & & & & & & & \\
\hline Fibeira & & & & & & $x$ & $x$ & $x$ & & & & & & & & & & & & \\
\hline Santiago & & & & & & $x$ & & & $x$ & $x$ & & & & & & & & & & \\
\hline Mmianzo & & & & & & $x$ & & & & & & & & & & & & & & \\
\hline$A_{s}$ Pontes & & & & & & & & & & & & & & & & & & & & \\
\hline Chantada & & & & & & & & & & & $x$ & & & & & & & & & \\
\hline Lugo & & & & $x$ & & & & & & & & $x$ & $x$ & & & & & & & \\
\hline Montorte & & & & & & & & & & & & $x$ & & $x$ & $x$ & & & & & \\
\hline Wllalba & & & & & & & & & & & & $x$ & & & $\hat{x}$ & & & & & \\
\hline Wheiro & & & & & & & & & & & & $x$ & & & & & & & & \\
\hline $\begin{array}{l}\text { OBarco de } \\
\text { Valdeorras }\end{array}$ & & & & & & & & & & & & & & $x$ & & & & & & \\
\hline 0 Carballiño & & & & & & & & & & & & & & $x$ & & & & & & \\
\hline Ourense & & & & $x$ & & & & & $x$ & & & & & $x$ & & & & & & \\
\hline veńn & & & & & & & & & & & & & & $x$ & & & & & & \\
\hline Lalin & & & & & & $x$ & $x$ & & & & & & & & & $x$ & & & & \\
\hline Ponteareas & & & & & & & & & & & & & & & & & $x$ & $x$ & & \\
\hline Pontevedra & & & & & & & & & $x$ & & & & & & & & & & $x$ & $x$ \\
\hline Vgo & & & & $x$ & & & & & $x$ & & & & & & & & $x$ & & & \\
\hline $\begin{array}{l}\text { Mlagaráa } \\
\text { de Arosa }\end{array}$ & & $x$ & & & & & & $x$ & & & & & & & & & & & $x$ & \\
\hline TOTAL & 3 & 4 & 1 & 4 & 1 & 4 & 2 & 2 & 4 & 1 & 1 & 4 & 1 & 5 & 2 & 1 & 2 & 1 & 2 & 1 \\
\hline
\end{tabular}

Fuente: Elaboración propia. 
Tabla 2. Concesiones de TDT-L a las principales empresas de comunicación de Galicia.

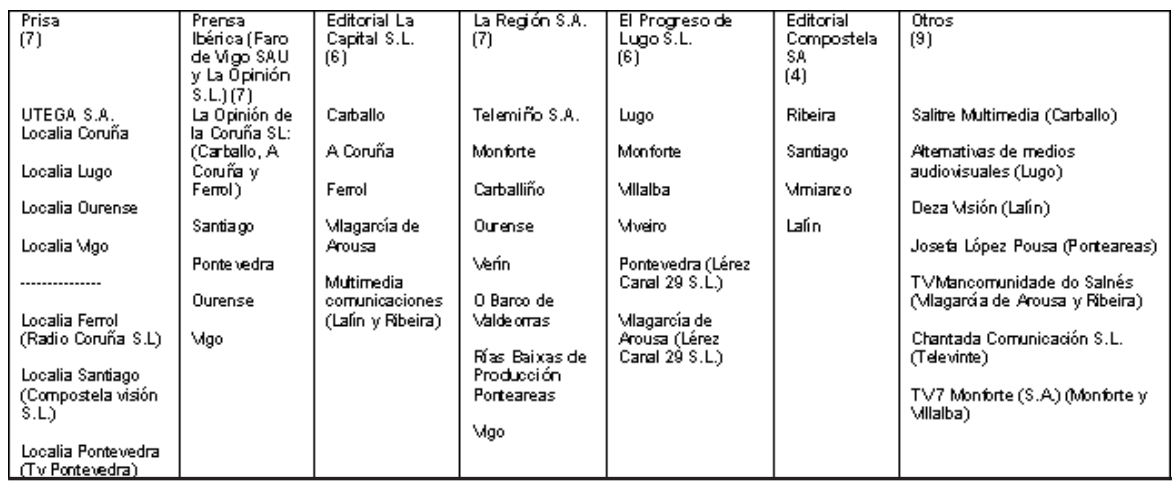

Fuente: Elaboración propia.

Tabla 3. Medios de comunicación de las empresas periodísticas que recibieron licencia de TDT-L.

\begin{tabular}{|c|c|c|c|c|}
\hline Prensa lbérica & |Editorial La Capital & La Región, S.A. & $\begin{array}{l}\text { EIProgreso de Lugo, } \\
\text { S.L. }\end{array}$ & $\begin{array}{l}\text { Editorial Compostela, } \\
\text { S.A. }\end{array}$ \\
\hline $\begin{array}{l}\text { Faro de Vigo, S.A.U. } \\
\text { La Opinión S.L. } \\
\text { TDT-L (7 licencias) }\end{array}$ & $\begin{array}{l}\text { Prensa escrita: } \\
\text { El Ideal Gallego } \\
\text { Diario de Ferrol } \\
\text { Diario de Arousa } \\
\text { Diario de Bergantiños } \\
\text { Deporte Campeón } \\
\text { TDT-L (6 licencias) }\end{array}$ & $\begin{array}{l}\text { Prensa escrita: } \\
\text { La Región } \\
\text { Rías Baixas de Producción } \\
\text { Atlántico Diario } \\
\text { Producción audiovisual: } \\
\text { Telemiño, S.A. } \\
\text { TDT-L (7 licencias) }\end{array}$ & $\begin{array}{l}\text { Prensa escrita: } \\
\text { El Progreso } \\
\text { Diario de Pontevedra } \\
\text { LV } \\
\text { A comarca do Eo } \\
\text { Agencia de noticias: } \\
\text { AGN } \\
\text { Producción audiovisual: } \\
\text { Productora Lugo Press } \\
\text { TDT-L (6 licencias) }\end{array}$ & $\begin{array}{l}\text { Prensa escrita: } \\
\text { El Correo Gallego } \\
\text { Galicia Hoxe } \\
\text { Radio: } \\
\text { Radio Obradoiro } \\
\text { Internet: } \\
\text { Elcorreo.es } \\
\text { Galiciahoxe.es } \\
\text { Radioobradoiro.es } \\
\text { Producción audiovisual: } \\
\text { Libro de Familia } \\
\text { Pratos combinados } \\
\text { Empresa de servicios de } \\
\text { comunicación: } \\
\text { Anova Multiconsulting } \\
\text { TDT-L (4 licencias) }\end{array}$ \\
\hline
\end{tabular}

Fuente: Elaboración propia.

Tabla 4. Reparto del mercado de población de TDT-L en Galicia.

\begin{tabular}{|c|c|c|}
\hline Grupo & Población & $\%$ Mercado \\
\hline Prisa & 1.529 .095 & $25,25 \%$ \\
\hline Prensa bérica & 1.462 .824 & $24,16 \%$ \\
\hline Editorial La Capital S.L. & 845634 & $13,97 \%$ \\
\hline La Región SA & 765.513 & $12,64 \%$ \\
\hline E Progreso de Lugo S.L. & 497093 & $21 \%$ \\
\hline Editorial Compostela SA. & 355370 & $5,87 x$ \\
\hline TV Salnés Barbanza & 236.739 & $3,91 \%$ \\
\hline Eurostar Producciones S.L & 107521 & \\
\hline & & $1,78 \%$ \\
\hline
\end{tabular}

Fuente: Elaboración propia. 


\section{SITUACIÓN ACTUAL}

Varias TVL que venían emitiendo en analógico no recibieron licencia digital. Es el caso de La 7 Televigo, Código Tv (Santiago), Telecoruña Canal, 41, TV Ferrol Canal 31, As Mariñas TV, TV Barbanza, Estrada TV-canal 57, RTV Cerdeda, TV de Arnoia, RTV Quiroga, Canal 50 TVL, Cablevisión do Carballiño. Algunas de ellas como La 7 Televigo han presentado recursos administrativos y están pendientes de la respuesta de la Xunta. Dependiendo de la resolución podrían recurrir al Tribunal Superior de Justicia de Galicia, lo que retrasaría en dos años la resolución del concurso de julio del año 2006. Una vez obtenida la respuesta de este Tribunal podrían recurrir al Tribunal Supremo, con lo que serían 4 años más de espera por una resolución favorable. Mientras no haya una resolución definitiva, las TVL que estaban emitiendo pueden seguir haciéndolo e incluso, si llegado del apagón analógico, no hubiese todavía resolución, el gobierno estaría obligado a dar un canal digital por el que emitir mientras no se resuelvan las apelaciones.

Es muy probable que el apagón tecnológico, previsto para 2008 en las TVL, se retrasará hasta el apagón general de 2010 por deseo expreso de la Xunta que así lo solicitó al Gobierno central. Las que están emitiendo y que llevan más de dos años podrían, por tanto, obtener un canal digital del Gobierno autónomo. Mientras tanto ya se han realizado algunas operaciones como las siguientes. Canal Tambre TV fue comprada por TV Salnés en noviembre de 2006. Código TV es una televisión local de Santiago que venía emitiendo en analógico y no recibió licencia digital. El grupo Correo compró el $51 \%$ de Código TV. La empresa sigue siendo Código TV pero la marca comercial es Correo TV que es quien lleva la gestión de la empresa. En estos momentos quien puede emitir en analógico es Código TV, de ahí que siga existiendo la empresa y de hecho es quien paga los repetidores y el personal, pero la licencia para emitir en digital sólo la tiene el grupo Correo. Código TV ha recurrido el concurso por vía administrativa, a la espera de que en breve reciba una respuesta. Si no, tiene previsto recurrir por vía judicial. Según declaraciones de la periodista de Código Cero, Raquel Noya, probablemente la Xunta de Galicia dará licencias a las emisoras que llevaban más de dos años emitiendo y que quedaron fuera del concurso. De este modo Código TV tendría licencia digital pero no se pondría a funcionar hasta 2010.

Los principales críticos al reparto de concesiones han sido el Bloque Nacionalista Galego (BNG), el Colexio Profesional de Xornalistas de Galicia (CPXG), el Sindicato de Xornalistas de Galicia (SXG) y algunas TVL que emitían hace años en analógico y no recibieron licencia.

Algunas emisoras de TVL denunciaron que el Gobierno Autonómico cambió algunas condiciones del concurso durante la ejecución de éste $(A D N, 7$ de julio de 2006). Parece un reparto poco favorable para la lengua gallega, para la pluralidad de contenidos, para el tejido empresarial gallego, ya que se puede dar una colonización del espacio de la TDT-L gallega por grandes cadenas que tienen su base operativa en Madrid. Se les garantizó el control audiovisual mayoritario en las ciudades y en las grandes áreas metropolitanas (http://www.vieiros.com, 11 de julio de 2006).

Se había pedido desde el CPXG que antes del reparto de TDT-L se hubiese creado el Consello do Audiovisual de Galicia, organismo que debería asumir entre otras 
competencias la de hacer una propuesta vinculante de reparto de las nuevas licencias audiovisuales. Entre las condiciones que se establecían en el concurso se concretaba: un $60 \%$ de programación de producción propia, de la que un $30 \%$ ha de ser en gallego, creación de empleo en el país. Varias emisoras locales agrupadas en Onda Nos y que no recibieron licencia pensaban que estaban en mejores condiciones de cumplir con estos requisitos que algunas de las adjudicatarias. Se favoreció a Prisa y a Prensa Ibérica coincidiendo con dos nuevos proyectos de comunicación en Galicia, el próximo periódico Faro de Galicia de Prensa Ibérica y la edidicón gallega de El País.

Las emisoras que han recurrido el concurso tienen la posibilidad, en opinión del colectivo Onda Nós, de seguir emitiendo en 2008, porque la previsión de resolución del conflicto, se estima en unos 15 años. Ello obligará al Gobierno a paralizar la concesión de licencias.

Por último, se incluyen los datos disponibles de las empresas que han recibido licencia de TDT-L. Al principio del artículo señalábamos como uno de los objetivos conocer las empresas que van a intervenir en el nuevo panorama pues es fundamental para anunciantes y público.

\begin{tabular}{|c|}
\hline Empresa: UTEGA SA(accionariado) \\
\hline $\begin{array}{l}\text { Accionistas: SER } 34 \% \text {. Prisa } 25 \% \text {. Banco Pastor } 11 \% \text {. Augas } \\
\text { de Coruña } 5 \% \text {. Europa TV } 122 \% \text {. Xavier Otero } 3 \% \text {. Prensa } \\
\text { Ibérica } 20 \% \text {, La Opinión } 5 \%\end{array}$ \\
\hline $\begin{array}{l}\text { Empresa: Alternativas de Medios Audiovisuales S.A. } \\
\text { Descripción de la actividad: Gestión indirecta de la televisión } \\
\text { local por ondas terrestres, la producción de todo tipo de } \\
\text { programas, redacción, edición. }\end{array}$ \\
\hline $\begin{array}{l}\text { Accionistas: Eurostar de Producciones S.L. Luis Miguel } \\
\text { Hernández Cardona, Gerardo Valles Iracheta. } \\
\text { Último año disponible: } 31 / 12 / 2004\end{array}$ \\
\hline
\end{tabular}

\begin{tabular}{|c|}
\hline $\begin{array}{l}\text { Empresa: Editorial Compostela S.A. } \\
\text { Descripción de la actividad: Publicacion, impresion y venta de } \\
\text { periódicos, revistas y publicaciones y en general toda clase de } \\
\text { tr abajos de imprenta y litografia. }\end{array}$ \\
\hline $\begin{array}{l}\text { Accionistas: Feliciano Barrera Fernández, José Manuel Rey } \\
\text { Nơoa, Ghaleb Jaber Ibrahim, Isabel Morate Roy. Alfredo } \\
\text { Goyanes Vilarino, Manuel Martinez Antelo, Julio Souto Boo, } \\
\text { José Pena Guitian, Fernando Barrera Morarte, Antonio Castro } \\
\text { Garcia. }\end{array}$ \\
\hline $\begin{array}{l}\text { Otras empresas: Anova Multiconsulting SA., Edicións Correo } \\
\text { S.A., Telecable Compostela S.A., Imuersiones Gallegas del } \\
\text { Cable S.A., Afianzamientos de Galicia Sociedad de Garantía } \\
\text { Reciproca, Economía Attántica S.A., Equinoccio SA., Ondas } \\
\text { Galicia S.A., Sociedad de Garantía Reciproca de la Pequeña y } \\
\text { Mediana Empresa de Pontevedray Orense. } \\
\text { Último año disponible: } 31 / 12 / 2005\end{array}$ \\
\hline \\
\hline
\end{tabular}




\begin{tabular}{|l|}
\hline Empresa: Chantada Comunicación S.L \\
\hline Descripción de la actividad: Prestacion de servicios de \\
radiodifusion televisiua por ondas hertzianas incluyendo todas \\
aquellas actividades relacionadas y conexas, en concreto, \\
senuicios de difusion, radio, television, enlace y trarsmis ion. \\
Accionistas: No hay datos disponibles \\
\hline Último año disponible: $31 / 12 / 2005$ \\
Fuente: Base de datos SABI \\
\hline
\end{tabular}

\begin{tabular}{l}
\hline Empresa: Deza Visión S.A. \\
\hline Descripción de Ia actividad: Senvicio de televisión local, ya \\
sea por ondas terrestres, via satelite o cable, como medio \\
audiouisual de comunicación social, y la emisión, producción y \\
distribución de programas de televisión. Promoción y \\
explotación. \\
Accionistas: No hay datos disponibles \\
\hline Ültimo año disponible: $31 / 12 / 2001$ \\
\hline Fuente: Base de datos SABI \\
\hline
\end{tabular}

\begin{tabular}{l}
\hline Empresa: Faro de Vigo Media S.L. \\
\hline Descripción de la actividad: Estudio, promoción y gestión de \\
toda clase de negocios relacionados con las técnicas, medios y \\
contenidos digitales, especialmente en los ámbitos de la \\
información electrónica, los bancos de datos y los cd rom. \\
\hline Accionistas: Editorial Prensa Ibérica, S.A.(47'50\%). Faro de \\
Vigo S.A.(47 $50 \%$ ). Francisco Jauier Moll de Miguel, M. \\
Aránzazu Sarasola Ormazábal. (información del año 2006) \\
\hline Último año disponible: $31 / 12$ / 2003 . \\
\hline Fuente: Base de datos SABI \\
\hline
\end{tabular}

\begin{tabular}{l}
\hline Empresa: Editorial La C apital S.L \\
\hline Descripción de Ia actividad: impresión, publicación y edición \\
de diarios, libros y folletos y cualesquiera otras publicaciones \\
periódicas o unitarias por cuenta propia y de terceros. \\
Proporcionar a terceros noticias, colaboraciones, fotografias. \\
Accionistas: Editorial C elta S.A. Artes Gráficas La Capital S.A. \\
\hline Último año disponible: $31 / 12 / 2004$ \\
Fuente: Base de datos SABI
\end{tabular}

\begin{tabular}{l}
\hline Empresa: El Progreso de Lugo S.L \\
\hline Descripción de la actividad: Composición, impresión y \\
edición, y por cualquier procedimiento y por cuenta propia o de \\
terceros, de prensa periódica y de toda clase de textos e \\
imágenes, asi como la explotación de emisoras de radio. \\
Accionistas: Antonio Purificación Cora Garcia, Blanca Cora \\
Garcia, José Cora Paradela, Gorzalo Cora Sierto, Blanca \\
Montenegro, \\
Otras empresas: Edicións Cultura Galega S.L., Lérez \\
Ediciones S.L.. Telelugo EI Progreso S.L., AGN Axencia Galega \\
de Noticias S.A. Televisión Lugo S.A. Cinfo Contenidos \\
Informatiosos personalizados S.L., Ondas Galicia S.A. \\
\hline Último año disponible: $31 / 12 / 2005$ \\
\hline Fuente: Base de datos SABI \\
\hline
\end{tabular}




\begin{tabular}{|l|}
\hline Empresa: Televisión da Mancomunidade do Salnés S.L \\
\hline Descripción de Ia adividad: Explotacion de una emizora de \\
televisión con sus senvicios accesorios. \\
Accionistas: No hay información disponible. \\
\hline Ültimo año disponible: $31 / 12 / 2005$ \\
\hline Fuente: Base de datos SABI \\
\hline
\end{tabular}

\begin{tabular}{|l|}
\hline Empresa: Rías Baixas de Producciones video y televisión S.A. \\
\hline Descripción de la actividad: Gestion indirecta del servicio de \\
televisión local por ondas terrestres. \\
Accionistas: La Región SA., Ouro S.A. \\
\hline Último año disponible: $31 / 12 / 2005$ \\
\hline Fuente: Base de datos SABI \\
\hline
\end{tabular}

\section{CONCLUSIONES}

1. Desde la ley de 1995 hasta 2002 se modificó el concepto de televisión local, ahora se habla ya de una modalidad de televisión consistente en la emisión o transmisión con tecnología digital.

2. Otra modificación que experimenta la TVL es que pasa de ser municipal a cubrir demarcaciones por número de habitantes.

3. En el año 2003 se autorizó la emisión en cadena.

4. Como se desprende de este artículo, la información es la base de los contenidos de las TVL, puesto que el resto de los programas se emiten en cualquier cadena de otro ámbito. La información es local, es lo más caraterístico de este tipo de televisiones.

5. La información de proximidad tiene unas características específicas, como son por ejemplo, facilitar la participación y el debate social y representar la realidad local y regional como distintas y relacionadas con la realidad nacional y transnacional.

6. El Real Decreto 439/2004 aprobó el Plan Nacional de Televisión Digital Local. A Galicia se le concedieron entonces 20 demarcaciones a la que en diciembre de ese año se añadió la demarcación de As Pontes. Cada emisora tendría un canal múltiple con capacidad para cuatro programas.

7. El Real Decreto de 3 de diciembre de 2004 modificó el anterior y situaba enero de 2008 como fecha límite para el apagón analógico de las locales.

8. España se divide en 281 demarcaciones a efectos de TDT-L.

9. La ley 10/2005 de medidas urgentes para el impulso de la TDT, de liberalización de la televisión por cable y fomento del pluralismo confirma y amplía el derecho pre- 
ferente de los ayuntamientos para gestionar de forma directa sus televisiones.

10. De todas las argumentaciones que se le demandan a una TVL la que mejor responde a su filosofía es la que asocia contenidos propios situados dentro de la realidad social de la comunidad en la que está ubicada la emisora.

11. En julio de 2006 el Gobierno de la Xunta de Galicia resolvió el concurso de TVL. Otorgó 46 licencias.

12. Observando la resolución de los concursos en las distintas comunidades autónomas se observa predominio de decisiones políticas y partidistas. Como consecuencia surge la polémica y las denuncias.

\section{REFERENCIAS BIBLIOGRÁFICAS}

IGLESIAS, Z. "La televisión local pública en España. La producción propia informativa como esencia de una verdadera comunicación de proximidad de servicio público". Disponible en http://www.unav.es/fcom/cicom/grupos.htm [Consulta: 27 de marzo de 2007].

MANEIRO, A. "A transición das TV locais á tecnoloxia dixital. Un cambio de modelo". Comunica, $\mathrm{n}^{\circ}$ 1, 2004.

ROMÁN, M. (2005). "La televisión local en España”. Sphera Publica, n 5, 2005, pp. 229-240.

- (2003) "Televisiones locales de Galicia". Estudios de Periodística, n 5, 1997, pp. 71-85.

- (1997) "La televisión local en el Estado Español". En VV.AA. Televisiones locales en Europa: Proximidad, Programación y Políticas de Comunicación. Santiago de Compostela: 2003.

VV.AA. Actas del primer congreso Luso-Gallego de Estudios Periodísticos.

http://actualidad.terra.es/sociedad/articulo/conmemoran aniversario nacimiento tele vision_local_340415.htm [Consulta: 26 de marzo de 2007].

http://www.g9tvlocal.com/base.swf [Consulta: 27 de marzo de 2007].

\section{Breve semblanza de la autora}

Mercedes Román Portas es Profesora Titular de Periodismo en la Facultad de Ciencias Sociales y de la Comunicación de la Universidad de Vigo (Campus de Pontevedra), en las que se dedica a la docencia e investigación en Historia y Teoría de la Comunicación y de la Información. 